\title{
Preparation and Characterization of Monolithic Poly(methacrylic acid - ethylene glycol dimethacrylate) Columns for High Performance Liquid Chromatography
}

\author{
Hongyuan Yan and Kyung Ho Row* \\ Center for Advanced Bioseparation Technology, Department of Chemical Engineering, Inha University, \\ Incheon 402-751, Korea. "E-mail: rowkho@imha.ac.kr \\ Received July 20,2005
}

\begin{abstract}
Porous polymer monolithic columns were prepared by the direct free radical copolymerization of methacrylic acid and ethylene glycol dimethacrylate within the confines of a chromatographic column in the presence of toluene-dodecanol as a porogenic solvent. The separation characteristics of the monolithic columns were tested by a homologous series of xanthine derivatives, theophylline and caffeine. The effects of the polymerization mixture composition and polymerization condition, mobile phase composition, flow rate and temperature on the retention times and separation efficiencies were investigated. The results showed that the selection of correct porogenic solvents and appropriate polymerization conditions are crucial for the preparation of the monolithic stationary phases. The separation efficiency was only extremely weakly dependent on flow rate and temperatures. Ilydrogen-bonding interaction played an important role in the retention and separation. Compared with conventional particle columns, the monolithic column exhibited good stability, ease of regeneration, high separation efficiency and fast analysis.
\end{abstract}

Key Words : Monolithic column, In-sim polymerization. Theophylline, Caffeine

\section{Introduction}

Monolithic columns, one of the most interesting innovations in column-manufacture technology, are also referred to in the literature as monolithic stationary phase, continuous bed, and rod columns. ${ }^{1-3}$ These columns have one common characteristic: they are made of one single piece of an adsorbent material (silica or polymer) that fills the entire length of the column., ${ }^{4}$ The large through-pores present in this type of stationary phase enable mobile phases to flow through the adsorbent with low flow resistance at high flow rates. ${ }^{6-10}$ Because of their ease of preparation, high reproducibility, versatile surface chemistry, and rapid mass transport, monolithic stationary phases have become a rapidly expanding field in chromatographic stationary phase preparation in recent years and some have even been commercialized. ${ }^{1-15}$ Their innovative development has led some chromatography researchers to regard them as fourthgeneration chromatography adsorbents. ${ }^{16}$

The most innovative feature of the monolithic columns compared to conventional particle beds is their unique porous structure. Conventional particle-based supports consist of a few, micrometer-sized, porous particles. Because the pores within the particles are in close proximity, the liquid inside them remains stagnant. Therefore, the molecules to be separated are transported to the active sites inside the closely packed pores and back to the mobile phase mainly by diffusion. Diffusion alone, however, is a rather slow process, especially in the case of large molecules with a low mobility. Monoliths, on the other hand, consisting of a single piece of porous material, are highly interconnected, and thereby form a network of channels and provide the large surface area needed to achieve sufficient capacity.
Meanwhile, the larger through-pores reduce the flow resistance and thus enable the use of high flow rates at considerably reduced backpressure. Since the flow of the liquid within the channels is driven by the pressure difference, the molecules to be separated are transported to the active sites located on the surface of the channels by convection. The separation efficiency is only extremely weakly dependent on flow rate; therefore, high separation efficiency can be maintained at significantly increased flow rates. $^{17}$

There are presently two main types of monolithic columns: silica ${ }^{18.19}$ and porous organic. ${ }^{20}$ Monolithic columns were introduced first for organic polymers in the late $1980 \mathrm{~s}$ and early $1990 \mathrm{~s}$. Although the column efficiency provided by polymer monolithic columns is generally lower than that by the silica particles in conventional columns, the polymeric monolithic column exhibits more potential advantages and has a more promising future than its silica-based counterparts because of the simpler preparation process, higher efficiency, easier pore size control, and more adaptability to adjust column selectivity. Organic polymer monolithic materials undergo easy, in situ synthesis through thermal or irradiation initiation, during which the pore properties and surface area of the material can be freely controlled by the type and composition of the porogenic solvent, crosslinker and polymerized condition. Given the variety of available monomers and crosslinkers, various separation requirements can be achieved with the polymer monolithic material which enables the production of different polarity and functional groups. Besides, the procedure for synthesizing such kind of material is simple and reproducible, and the polymer monolithic material can be easily situated in the separation support structure, i.e. stainless steel column and cartridges, 
without any additional packing step, which also makes it an attractive alternative for applications such as separation media. ${ }^{21-23}$ However, there is still a distinet lack of systematic investigation into the fabrication of monolithic columns. In addition, new preparation methods for monolithic columns need to be developed for various different materials duc to their special structure.

In the present study, polymer monolithic columns using methacrylic acid as the acidic monomer and ethylene glycol dimethacrylate as the crosslinker were prepared by a simple, onc-step, in-situ, frec-radical polymerization, "molding" process, directly within the confines of a chromatographic column. The characteristies of the monolithic columns were tested by a homologous series of xanthine derivatives, theophylline and eaffeine. ${ }^{24}$ The effects of the polymerization mixture composition and polymerization condition, mobile plase composition, flow rate and temperature on the retention times and separation efficieneies were investigated. Compared with conventional particle columns, the monolithic column exhibited good stability, ease of regeneration and high-efficiency separation ability.

\section{Experimental Section}

Materials. Caffeine and theophylline were obtained from Sigma (ST Louis, MO, USA). The structures of these molecules were shown in Figure 1. Methacrylic acid (MAA) was purchase from Kanto Chemical Co., Ine, (Japan). T:thylene glycol dimethacrylate (ГБDMA) was obtained from Tokyo Kasci Kogyo Co., LTD (Tokyo, Japan), $\alpha, x^{\prime}$-Azobis (isobutyronitrile) (AIBN) was the product of Junsei Chemical Co., Lid. (Japan). Toluene was purchased from Orienal Chemical Industrics (Japan). Dodecyl alcohol, acetonitrile, chloroform and methanol are all of HPLC grade and from Duksan Pure Chemical Co., LTD (Ansan, Korea). Acetic acid (analytical grade) was purchased from Oriental Chemical Industries (Incheon, Korea). Double distilled water was filtered with $0.45 \mathrm{~mm}$ filter membrane before use.

Preparation of monolitlic column. The monolithic columns were prepared by a direct in sint polymerization within stainless steel of a $150 \mathrm{~mm} \times 3.9 \mathrm{~mm}$ I.D. chromatographic column. The polymerization mixture composed of methacrylic acid. Ethylene glycol dimethacrylate (EDMA)<smiles>CC1C(=O)N(C)C(=O)c2c1ncn2C</smiles>

(1)<smiles>CC1C(=O)N(C)C(=O)c2[nH]cnc21</smiles>

(2)
Figure 1. Molecular structures of caffeine (1) and theophylline (2).

and $\alpha, \alpha^{\prime}$-Azobis (isobutyronitrile) (AIBN) was dissolved in the porogenic solvents (toluene and dedecanol) (Table 1). The mixture solution was put into supersonic for $15 \mathrm{~min}$, sparged with helium for $10 \mathrm{~min}$ to remove oxygen. The stainless-stecl tube sealed at the bottom was filled with the above polymerization mixture and then sealed at the top. The polymerization was perfomed in a water bath with the temperature maintained at $45{ }^{\circ} \mathrm{C}$ for $12 \mathrm{~h}$. After the polymerization, the seals were removed; the column was connected to HPI.C pump and washed respectively with tetraliydrofurana for three hour and methanol/acetic acid $(80$ : $20 \% \mathrm{w} / \mathrm{v}$ ) four hour to remove the porogenic solvents and other soluble compounds present in the polymer monolith after the polymerization was completed.

HPI C analysis. Separation characteristics of the monolithic column were analyzed by a licjuid chromatography system containing Waters 600 s Multisolvent Delivery System and a Waters 616 pump (Waters, Milford, MA, USA), Waters 2487 Dual Absorbance UV detector (Waters, Milford, MA, USA) and Rheodyne injection valve (20 $\mu \mathrm{L}$ sample loop). The Millennium 32 software (Waters, Milford, MA, USA) was used as data aequisition system. LiChrospher ${ }^{k} 100$ RP$18(12 \mu \mathrm{m})$ and Lichrospher ${ }^{k}$ Silica $(15 \mu \mathrm{m})$ was purchasc from Merck (Germany). Acetonitrile was used as mobile phase, UV wavelength at $270 \mathrm{~nm}$.

The separalion factor $(\alpha)$ was determined by the following equation:

$$
\alpha=k_{2} / k_{1}
$$

Where $k_{2}$ is the retention factor of theophylline and $k_{1}$ is the retention factor of caffeine. The retention factor was determined by

$$
\left.k=\left(t_{i}-t_{i}\right) / t_{i}\right)
$$

Table 1. Ffect of differents porogenic solvents on the separation characteristic of monolithic column. (Separated condition: mobile phase: acetonitrile, flow rate: $0.5 \mathrm{~mL} / \mathrm{min}$, detection wavelength: $270 \mathrm{~nm}, k_{1}$; the retention factor of caffeine, $k_{2}$ : the retention factor of theophylline, $R$, resolution of cafteine and theophylline)

\begin{tabular}{ccccccccc}
\hline No. & $\begin{array}{c}\text { MAN } \\
(\mathrm{mL})\end{array}$ & $\begin{array}{c}\text { Г.DMA } \\
(\mathrm{mL})\end{array}$ & $\begin{array}{c}\text { Toluenc } \\
(\mathrm{mL})\end{array}$ & $\begin{array}{c}\text { Cyclohexanol } \\
(\mathrm{mL})\end{array}$ & $\begin{array}{c}\text { Dodecanol } \\
(\mathrm{ml})\end{array}$ & $k_{1}$ & $k_{2}$ & $R$. \\
\hline 1 & 0.085 & 0.945 & - & - & $2.000-4.000$ & $<0.250$ & $<0.308$ \\
2 & 0.085 & 0.945 & $2.000-4.000$ & - & - & & High pressurc \\
3 & 0.085 & 0.945 & 1.250 & - & 1.250 & 0.284 & 1.098 & 0.892 \\
4 & 0.085 & 0.945 & 1.000 & - & 3.000 & 0.326 & 1.307 & 1.127 \\
5 & 0.085 & 0.945 & 0.600 & - & 1.680 & 0.420 & 1.334 & 1.938 \\
6 & 0.085 & 0.945 & - & 0.600 & 1.680 & 0.214 & 1.056 & 0.842 \\
\hline 7 & 0.085 & 0.945 & - & $1.000-2.000$ & 1.000 & $<0.210$ & $<1.124$ & $<1.328$ \\
\hline
\end{tabular}


Where $t_{i}$ is the retention time of the solute and $t_{0}$ is void time of the column, which was detemined by acetone as the void marker. ${ }^{25}$ All the procedures were carried out at the room temperature.

\section{Results and Discussion}

Comparisons with traditional particle column. The obvious advantage of monolithic column is their porous,
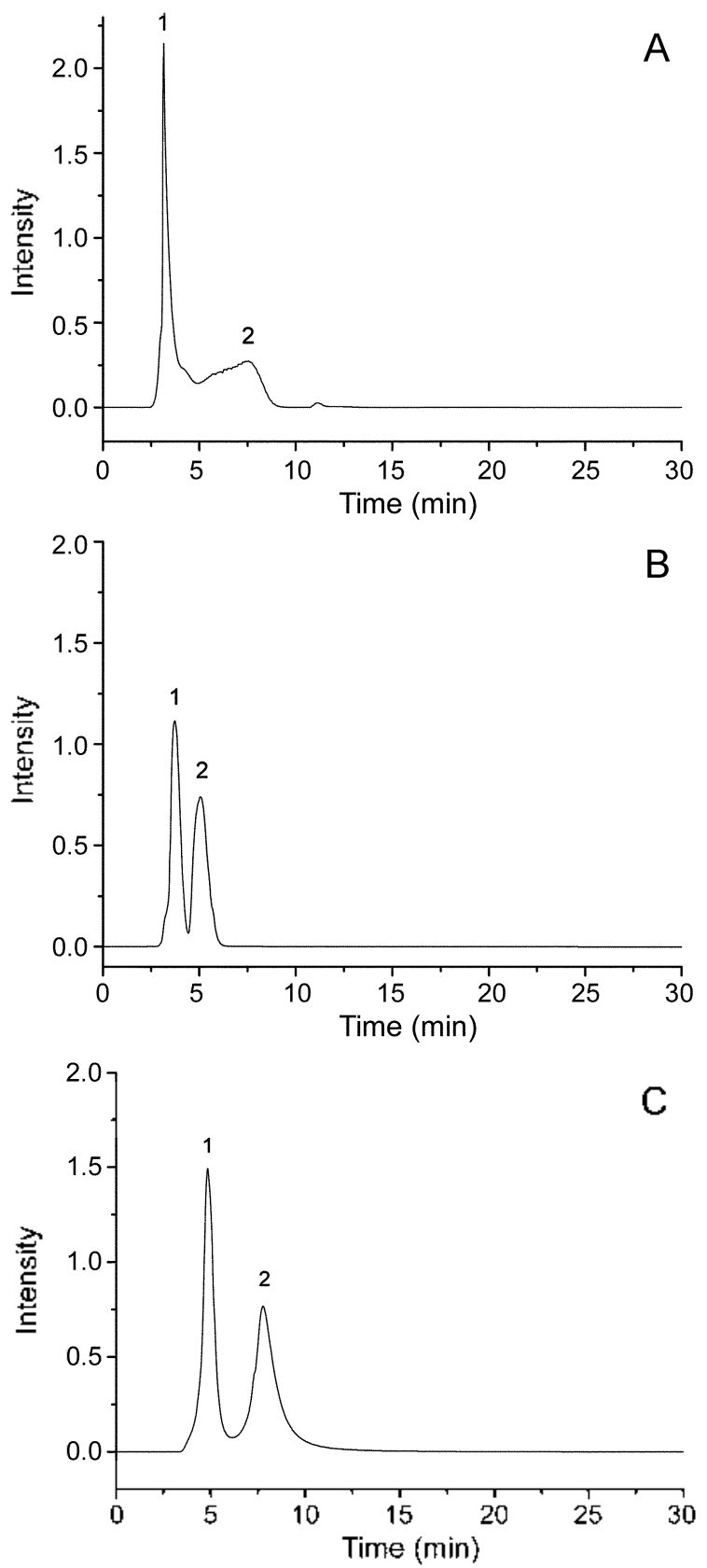

Figure 2. Chromatograms of caffeine and theophylline on different columns. (A: Chromatograms on lichrospher ${ }^{R} 100$ RP-18 particle column, B: Chromatograms on Lichrospher" Silica column, C: Chromatograms on polymer monolithic column, mobile phase: A: $20 \%$ acetonitrile $+80 \%$ water; $B$ : methanol; $\mathrm{C}$ : acetonitrile, flow rate: $0.5 \mathrm{ml} / \mathrm{min}$, detection wavelenglh: $270 \mathrm{~nm}$, peak l: cafleine; peak 2: theophylline) highly interconnected network structure, which supports the formation of a network of channels and provides the large surface area needed to achieve sufficient capacity. Compared to the conventions packed column, in which high efficiency and high speed are mutually exelusive, the monolithic column allows a high flow rate which enables faster separation and lower consumption of mobile phase. In this experiment, I ithospher ${ }^{k} 100$ RP-18 particle column and I.ichrospher ${ }^{k}$ Silica column were used as conventional particle columns and compared with the monolithic column at different separation condition. Water, methanol, acetonitrile, 2-propanal and hexane were used as mobile phase respectively. At the optimized condition, theophylline and caffeine can't be completely separated on conventional Lithospher $^{k} 100$ RP-18 particle column and better separation was obtained at the I ichrospher ${ }^{k}$ Silica column (Figure 2). The retention time of the samples on Silica column inereased with the polar decreasing of mobile phase, but the separation factor not increased obviously because the peaks broaden. Theophylline and caffeine can't be washed out within $60 \mathrm{~min}$ if using more than $60 \%$ of hexane in $2-$ propanol as mobile phase. Moreover, the separation efficiency decreased and column pressure increased obviously with the increasing of mobile phase flow rate on the traditional particle column. Theophylline and caffeine can be absolute separation on the monolithic column using acetonitile as mobile phase. The influenee of flow rate variation on the separation efficiency is shown in Table 2 . The chromatographic efficiency decreased obviously with the increasing of flow rate on the conventions packed column because the pores within the particles are close to each other and the liquid inside them is stagnant. Therefore, the molecules to be separated are transported inside the close pores and back to the mobile phase mainly by diffusion. Compared to the conventions packed column, the monolithic column shown an extremely small dependeney of separation efficiency on flow rate is due to the flow of the liquid within the macropore network channels is driven by

Table 2. Separation characteristic of theophylline and calleine at different flow rates. (No. 1-6: polymer monolithic column, No. 7-8: Lichrospher ${ }^{R}$ Silica column, $k_{1}$ : the retention factor of catfeine, $k_{2}$ : the retention factor of theophylline, $x$ : separation factor of caffeine and theophylline, $N_{1}$ : the number of plates for calleine, $N_{2}$ : the number of plates for theophylline, $R$. resolution of eaffeine and theophylline)

\begin{tabular}{cccccccc}
\hline No. & Flow rate & $k_{1}$ & $k_{2}$ & $\alpha x$ & $N_{1}$ & $N_{工}$ & $R_{3}$ \\
\hline 1 & $0.2 \mathrm{~mL} / \mathrm{min}$ & 0.443 & 1.386 & 3.126 & 490 & 207 & 2.039 \\
2 & $0.3 \mathrm{~mL} / \mathrm{min}$ & 0.431 & 1.331 & 3.086 & 459 & 222 & 2.006 \\
3 & $0.5 \mathrm{~mL} / \mathrm{min}$ & 0.420 & 1.334 & 3.175 & 476 & 195 & 1.938 \\
4 & $1.0 \mathrm{~mL} / \mathrm{min}$ & 0.428 & 1.251 & 2.923 & 461 & 191 & 1.827 \\
\hline 5 & $2.0 \mathrm{~mL} / \mathrm{min}$ & 0.420 & 1.219 & 2.902 & 443 & 182 & 1.791 \\
\hline 6 & $3.0 \mathrm{~mL} / \mathrm{min}$ & 0.416 & 1.203 & 2.892 & 438 & 180 & 1.785 \\
\hline 7 & $0.5 \mathrm{~mL} / \mathrm{min}$ & 0.292 & 0.598 & 2.048 & 340 & 196 & 1.126 \\
\hline 8 & $1.0 \mathrm{~mL} / \mathrm{min}$ & 0.266 & 0.501 & 1.883 & 308 & 162 & 0.887 \\
\hline
\end{tabular}


the pressure difference and the molecules to be separated are transported by convection. From Table 2 we could sec the monolithic column allowing the separation efficiency to be maintained at significantly increased flow.

Fffect of the preparation condition of the monolithic column. The proportion of mixture composition and polymerization temperature defines the monolithic structure and separation characteristic without further processing. Although the preparation process of the monolithic stationary plases is quite simple, a few factors have to be taken into account, of which the selection of the porogenic solvents is crucial for the preparation of the monolithic stationary phases. Firstly, the initiator, monomer and crosslinker have to be soluble in the porogenic solvents. Secondly, the porogenic solvents should produce large pores, in order to assure good flow-through properties of the resulting polymer. In this study, several porogenic solvents, including eyclohexanol, dodecanol, and toluene, were tested for their compatibility. The monolithic stationary phases using cyclohexanol and dodecanol as porogenic solvents showed low selectivity for theophylline and eaffeine. Meanwhile, monolithic stationary phases with high selectivity and low backpressure could be obtained using the low polar porogenic solvents of toluene and dodecanol as porogenic mixture. The ratio of toluene and dodecanol also affected the separation performance through variation in pore structure of the monolithic stationary phases. With inereasing toluene proportion, the mean pore size decreased and the specific area and resolution factor increased. However, when the proportion of toluene in the porogenic mixture rose abowe $30 \%$, the pore diancter of the resulting stationary phase was too small to allow the mobile phase to flow through. Thus, in linding a balanee between the recuirements of low flow resistance and large surface area, a ratio of $26 \%$ toluene and $74 \%$ dodecanol was used in this experiment as the optimal porogenic mixture.

The polymerization conditions of temperature and time affect the efficiency and selectivity of the resultant polymeric stationary phases. The commonly used polymerization temperature is $60^{\circ} \mathrm{C}$. Although complete polymerization was achieved in $4 \mathrm{~h}$ at $60^{\circ} \mathrm{C}$ in the present study, the initiation of the polymerization reaction was very fast and therefore hard to control at this temperature. This reduced the reproducibility of the monolithic stationary phases. Furthermore, the relatively high temperature had a negative impact on the complex stability, which reduced the reproducibility of the monolithic stationary phases and produced high column pressure drops. Thus, the relatively low temperature of $45^{\circ} \mathrm{C}$ with a prolonged reaction time of $12 \mathrm{~h}$ was selected in order to yield a more reproducible polymerization. The reaction time of $12 \mathrm{~h}$ was chosen because the polymerization remained incomplete at less than $9 \mathrm{~h}$, whereas the column pressure increased at more than $12 \mathrm{~h}$.

Effect of the mobile pliase composition. In this study, the effect of mobile phase composition on the separation was investigated using methanol, water and acetonitrile, with the



Fignre 3. Effect of mobile phase composition on retention factor and separation lactor. (mobile phase: acelonilrile, flow rale: 0.5 $\mathrm{mL} / \mathrm{min}$, detection wavelength: $270 \mathrm{~nm}, k_{3}$ : the retention factor of cafteine, $k_{2}$ : the retention factor of theophylline, $a$ : the separation factor of caffeine and theophylline)

latter showing the best separation. The effects of polar additives in the mobile plase were also evaluated with mixtures of acetonitrile-acetic acid as the mobile phase (Figures 3 and 4). The experiment showed that with the increasing of the solvent polarity in the mobile phase, the retention factors of caffeine and theophylline all decreased. The best retention factor was attained with $100 \%$ acetonitrile as the mobile phase. These results can be explained by the presence of ionic pair and hydrogen-bonding interactions between the stationary phase and the sample. In our experiment, methacrylic acid was used as the monomer and its carboxyl group is the most common hydrogen-bonding and acidic functional group. From the molecular strueture of theophylline and caffeine, the only evident differences between the two templates lay in $N^{*}$. For the cafleine molecule, the hydrogen on $\mathrm{N}^{*}$ was placed by methyl, whereas active hydrogen still existed on $\mathrm{N}^{*}$ in theophylline. So the amino group in theophylline could form a hydrogen bond by the active hydrogen on $\mathrm{N}^{*}$ with the carboxyl in methacrylic acid. In addition, the near oxygen and nitrogen also could form a hydrogen bond with the carboxyl in the monomer. For the caffeine molecule, no active hydrogen was offered for forming the hydrogen bond on $N^{*}$. Moreover, the volume of the methyl group was much large than that of hydrogen; it could, therefore, block the hydrogen bond forming by steric hindrance. Hence, theophylline exhibited excessively long retention times and peak tailing on the monolithic column. As the polar additives can interfere with the hydrogen-bonding interactions between the carboxylic acid of methacrylic acid in monolithic columns and the functional group of the analytes, the retention factors of caffeine and theophylline decreased with increasing content of the polarity solvent in the mobile phase.

Effect of the flow rate on the separation efficiency. Monolithic columns have been studied as materials, with the inherent advantages of their network-type, one-piece struc- 

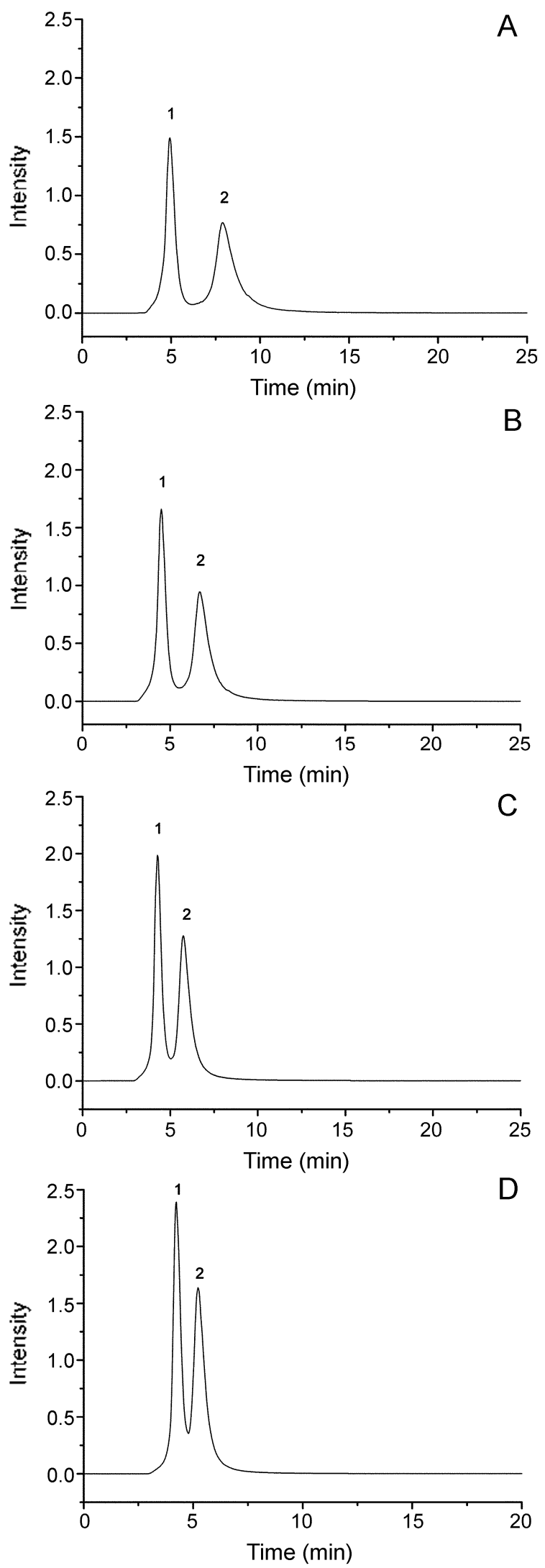

Figure 4. Chromatograms of catteine and theophylline at difterent mobile phase composition. (mobile phase: 1 : acetonitrile; $2: 99.5 \%$ acetonitrile $10.5 \%$ acetic acid; $3: 98 \%$ acetonitrile $12 \%$ acetic acid; 4: $96 \%$ acetonitrile+4\% acetic acid, flow rate: $0.5 \mathrm{~mL} / \mathrm{min}$, detection wavelength: $270 \mathrm{~nm}$, peak I: caffeine; peak 2 : theophylline)

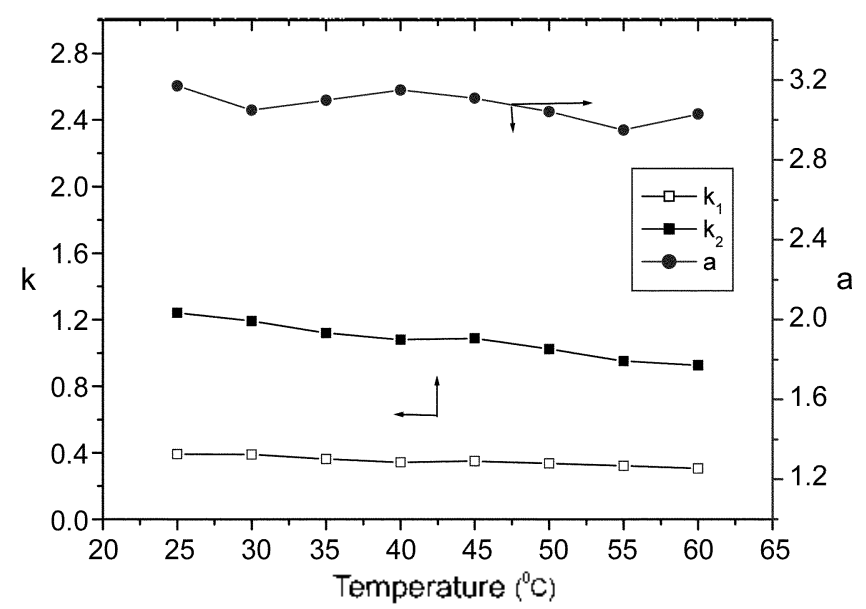

Figure 5. liffect of dilferent temperatures on the separalion factor and retention factor. (mobile phase: acetonitrile, flow rate: $0.5 \mathrm{~mL} /$ min, detection wavelength: $270 \mathrm{~nm}, k_{1}$ : the retention factor of caffeine, $k_{2}$ : the retention factor of theophylline, $a$ : separation factor of cafleine and theophylline.)

tures. The microseopic structure of monolithic columns is porous and composed of two interconnected networks of pores. Through-pores provide flow paths through the column, and the size and density of the macropore network gives the monolithic columns a high external porosity and, conseguently, a large permeability and low column hydraulic resistanee. The network of mesopores is responsible for the large specific surface area of the monolith, henee for the retention volumes observed for most analytes. For these reasons, the monolithic columns are efficient at high flowrates and can also be used in long, connected series, thereby giving very high efficiencies. In this study, the flow rate of the mobile phase was investigated over the range of $0.2-3.0$ $\mathrm{mL} / \mathrm{min}$ (Table 2). Although the migration times of the caffeine and theophylline decreased with increasing flow rate, only a slight decrease of the separation efficiency was found with increasing flow rate. The results showed an extremely small dependency of separation efficiency on flow rate, thereby allowing the separation efficiency to be maintained at significantly increased flow rates. This is the typical characteristic of monolithic columns.

Effect of temperature on the separation efficiency. The effects of temperature, over the range from $25^{\circ} \mathrm{C}$ to $60^{\circ} \mathrm{C}$, on the separation were also investigated (Figure 5). The results showed that at higher temperature, both theophylline and caffeine migrated fast, and that theophylline changed faster than caffeine. Both $k_{1}$ and $k_{2}$ decreased with increasing temperature because the adsorption of the analytes to the substrate weakened with increasing temperature, allowing the analytes to migrate faster through the monolithic column. Furthermore, the separation factors decreased with increasing elution temperature, because the higher temperature decreased the interaction between the theophylline and the polymers more than that between the caffeine molecule and the polymers. Therefore, a lower temperature will lead to a higher separation. However, with increasing column temperature, the separation and retention factors were only slightly 
changed. The results demonstrated that the dependency of separation efficiency on temperature is small, and that high separation efficiency can be maintained under higher temperature.

\section{Conclusion}

The results showed that the mixture composition proportion and the polymerization condition combine to define the monolithic structure without further processing. Therefore, the proper selection of porogenic solvents and polymerization temperature is crucial for the preparation of the monolithic stationary phases. The method of in situ polymerization is simple and rapid, with a low consumption of chemicals. Moreover, the dependency of separation efficiency on flow rate and temperatures is extremely small and hydrogen-bonding interaction plays an important role in the retention and separation. The study results presented here have substantiated the significant research interest in monolithic columns compared with conventional particle columns due to their ease of preparation, high separation efficiency, and rapid mass transport.

Acknowledgement. The authors gratefully acknowledge the financial support of the center for Advanced Bioseparation Technology, Inha University.

\section{References}

1. Minakuchi, H.; Nakanishi, K.; Soga, N.; Ishizuka, N.; Tanaka, N. Anal. Chem. 1996, 68, 3498.

2. Tanaka, N.; Kobayashi, H.; Nakanishi, K.; Minakuchi, H.; Ishizuka, N. Antl. Chem. 2001, 73,420A.

3. Nakanishi, K. J. Porots Materials 1997, 4,67.

4. Svec, F.; Pelers, E. C.; Sykora, D.; Yu, C.; Frechet, J. M. J. J. High
Resolut. Chromatog: 2000,23,3.

5. Motokawa, M.; Kobayashi, H.; Ishizuka. N.; Minakuchi, H.; Nakanishi, K.; Jinnai, H.; Ikegami, T.; Tanaka, N. J. Chromatogr. A 2002, $961,53$.

6. Gusev, I.; Huang, X.; Horvath, C. J. Chromatogr. A 1999, 855, 273.

7. Jin, W; Fu, H.; Huang, X.; Xiao, H.; Zou, H. Electrophoresis $2003,24,3172$.

8. Minakuchi, H.; Nakanishi, K.; Soga, N.; Ishizuka, N.; Tanaka, N. J. Chronatogr, $A$ 1998, 797, 121 .

9. Allen, D.; Rassi, Z. J. Chromatogr. A 2004, 1029, 239.

10. Chankvetadze, B.; Yamamoto, C.; Okamoto, Y. Chem. Lett. 2003, 32,850 .

11. Kimura, H.; Tanigawa, T.; Morisaka, H.; Ikegami, T.; Hosoya, K.; Ishizuka, N.; Minakuchi, H.; Nakanishi, K.; Ueda, M.; Cabrera, K.; Tanaka, N. J. Sep. Sci. 2004, $27,897$.

12. Tanaka, N.; Kimura, H.; Tokuda, D.; Hosoya, K.; Ikegami, T.; Ishizuka, N.; Minakuchi, H.; Nakanishi, K.; Shintani, Y.; Furuno, M.; Cabrera, K. And. Chen. 2004, 76, 1273.

I3. Xu, Q.; Mori, M.; Tanaka, K.; Ikedo, M.; Hu, W. J. Chromatogr. A 2004. $1026,191$.

14. Lubda, D.; Lindner, W. J. Chromatogr: A 2004, 1036, 135.

15. Ikegami, T.; Tanaka, N. Anal. Tech. 2004, \&, 527.

16. Liu, H. Y,; Row, K. H.; Yang G L. Chromatographia 2005, 61, 429.

17. Ishizuka, N.; Kobavashi, H.; Minakuchi, H.; Nakanishi, K.; Hirao, K.; Hosoya, K.; Ikegami, T.; Tanaka, N. J. Chromatogr A 2002. 960.85.

18. Cabrera, K.J. Sep. Sci. 2004, 27, 843.

19. Ko, J. H.; Kang G. W,; Seo, Y. J.; Cheong, W. J. Bull. Korenn Chem. Soc. 2004, 25, 1589.

20. Svec, F. J. Sep. Sci. 2004, $27,747$.

21. Asperger, A.; Efer, J.; Koal, T.; Engewald, W. J. Chronatogr. $A$ 2002,960, 109 .

22. Sykora, D.; Svec, F.; Frechet, J. M. J. J. Chromatogr, A 1999, 852, 297.

23. Fan, Y.; Feng, Y. Q.; Da, S. L.; Shi, Z. G Analytica Chimica Acta $2004,523,251$.

24. Wang, D. X.; Hong, S. P.; Row, K. H. Bull. Korean Chem. Soce. 2004, 25, 357

25. Yin, J. F.; Yang, G L.; Chen, Y. J. Chromatogr. A 2005, $1090,68$. 